\title{
Observation Study on the Size Distribution of Sand Dust Aerosol Particles over Yinchuan, China
}

\author{
Jiandong Mao, Hongjiang Sheng, Hu Zhao, and Chunyan Zhou \\ School of Electrical and Information Engineering, Beifang University of Nationalities, Yinchuan 750021, China \\ Correspondence should be addressed to Jiandong Mao; mao-jiandong@163.com
}

Received 25 November 2013; Revised 24 January 2014; Accepted 28 January 2014; Published 5 March 2014

Academic Editor: Gwo-Fong Lin

Copyright (C) 2014 Jiandong Mao et al. This is an open access article distributed under the Creative Commons Attribution License, which permits unrestricted use, distribution, and reproduction in any medium, provided the original work is properly cited.

\begin{abstract}
The Yinchuan area, which lies in the eastern part of Northwest China, is one of the main transportation paths and origins of sand dust in China. In order to investigate the aerosol number size distribution and its temporal-spatial evolution over this area, direct solar radiation data taken from September 2012 to October 2013 by a sun photometer CE-318 located at Beifang University of Nationalities $\left(106^{\circ} 29^{\prime} \mathrm{E}, 38^{\circ} 13^{\prime} \mathrm{N}\right)$ were analyzed. The particle number size distributions were retrieved from the aerosol optical depth (AOD) by use of the extinction inversion method. The experiment results show that although the averaged size distribution satisfies basically the Junge function, there are two obvious peaks at the particle radius of $0.6 \mu \mathrm{m}$ and $1.4 \mu \mathrm{m}$, respectively. Because sand-dust weather occurs frequently, the particle size distribution in Spring is obviously larger than that in other seasons, which coincides with AOD variation tendency. Moreover, in sand-dust weather the particles number concentration is larger than that of background weather with one order of magnitude, especially for the number of concentration of large particles and giant particles. The research results have very important reference value for quantitative study of the influence of aerosol on atmosphere physics and chemistry process and monitoring of sand-dust weather and air pollution of this area.
\end{abstract}

\section{Introduction}

Sand dust aerosol, originated from arid and semiarid region of China, is the main component of aerosol in troposphere atmosphere of East Asia, which produces extensive influence on the ecosystem, atmosphere environment, and atmosphere chemistry through intensive sand dust storm weather process [1]. In order to study quantitatively the influence of aerosol on atmosphere physics and chemistry process, researchers have to analyze physics and chemistry characters of atmospheric aerosol in detail, including the number concentration, phase state, size distribution, and chemistry component. Therefore the observation of sand dust aerosol of typical region is very important for us to study the physics and chemistry properties of aerosol [2].

In the past several decades, some research teams have carried out many observation experiments to investigate the optical, microphysics, and chemical properties of sand dust aerosol by using some instruments, such as sun photometer, aerodynamic particle size spectrometer, optical particle counter, Andersen sampler, and lidar. In 1991 D’Almeida et al. researched the global aerosol optical character, including deserts area [3]. In 1997 Porter and Clarkepresented an aerosol size distribution model summarizing measurements of sulfate, sea salt, and dust aerosol obtained in the marine boundary layer and marine free troposphere [4]. In 1999 Karyampudi et al. performed a detailed synoptic analysis of 16 September to 19 September, 1994, Saharan dust outbreak over the eastern Atlantic and of its origin at over West Africa during the September 12 to 15 periods [5]. In the west and north region of China some observations on particle size distribution were also conducted. For example in $1995 \mathrm{Li}$ et al. used the dust counter and solar spectrometer measure and analyzed the atmospheric AOD and particle size distribution in three places of North China: Inner Mongolia, Beijing, and Xinxiang region, respectively [6]. During April to May of 1996 to 1999, Niu et al. employed the APS-3310A to measure and analyze the sand aerosol particle size distribution in the desert areas on both sides of the Helan Mountains under different weather conditions, including the background, dust, 


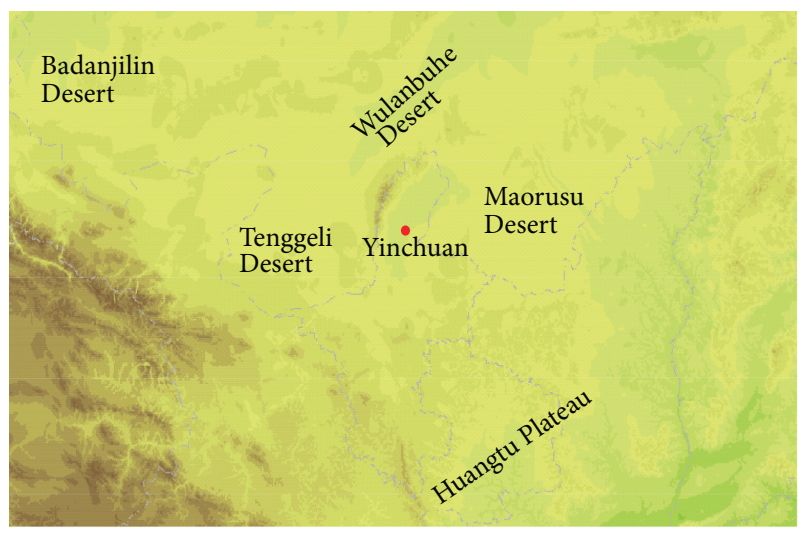

Figure 1: Map of the part of the northwest of China.

sand blowing, and sandstorm [2]. In2006 Liu and Niu used a CE-318 sun photometer to retrieve the AOD and size distribution by extinction method in Inner Mongolia and the results show that there were significant variations in temporal special distributions of AOD [1]. In 2010 Mao et al. used a compact Mie scattering lidar system for the first time to measure the optical properties and temporal-spatial distribution of atmospheric aerosol particles from 1 to 10 April over Yinchuan area [7].

The Yinchuan area lies in the eastern region of Northwest China. It belongs to the typical temperate continental climate and has some special features, such as drought, little rain, enough sunshine, strong evaporation, and big wind sand. Deserts, such as Badanjilin desert, Wulanbuhe desert, Tenggeli desert, and Maowuso desert, are located in the northwest, west, and east of Yinchuan area. These deserts are one of the main sand dust sources of East Asia. Figure 1 shows the map of the part of the northwest of China. Therefore, Yingchuan area is one of the main transportation path and original source of sand dust. The observations and analyses on aerosol properties over this area have very important reference value for quantitative study of the influence of aerosol on atmosphere physics and chemistry process and monitoring of sand-dust weather and air pollution.

For investigation of the aerosol number size distribution and its temporal-spatial evolution over this area, a series of systematically observation experiments were carried out by means of a sun photometer and many direct solar radiation data were obtained. By use of the extinction inversion method, the particle size distribution is retrieved from the AOD. In Section 2 the retrieval method of size distribution based on extinction method is discussed in detail, in Section 3 some experiments were carried out, and the results are analyzed in detail. Finally, a conclusion is given in Section 4 .

\section{The Retrieval Method}

The sun photometer CE-318 can acquire the AOD value simply. In fact, through the inversion of AOD the particle size distribution can be obtained $[8,9]$. Assuming that the particulates in the atmosphere can be accurately modeled by equivalent spheres whose refractive index is known, according to extinction method the relationship between the $\mathrm{AOD}$ and particle size distribution can be given by $[6,10]$

$$
\tau(\lambda)=\int_{0}^{\infty} \pi r^{2} Q_{e}(r, \lambda, m) n(r) d r,
$$

where $\tau(\lambda)$ is the AOD passing through the whole atmosphere, $n(r)$ is the aerosol size distribution of vertical column through the whole atmosphere, $r$ is particle radius, $m$ is complex refractive index of aerosol particles, and $Q_{e}(r, \lambda, m)$ is the extinction efficiency factor according Mie's theory. It is clear that this equation is the first kind of Fredholm integral equations.

The aerosol size distribution $n(r)$ can be described as a product form by two functions, namely, $n(r)=f(r) h(r)$, where $f(r)$ and $h(r)$ are the slowly varying function and the rapidly varying function, respectively. According to the Phillips-Twomey constraint inversion equation [11], one can obtain $[6,10]$

$$
\vec{f}=\left(A^{T} A+\gamma H\right)^{-1} A^{T} \vec{\tau}
$$

where $A$ is the coefficient matrix, $A^{T}$ is transpose of $A$, and $\gamma$ is the nonnegative Lagrange multiplier. $H=K^{T} K$ is the smoothing matrix and $K$ can be defined as [12]

$$
K=\left[\begin{array}{cccccccccc}
0 & 0 & 0 & 0 & 0 & . & . & 0 & 0 & 0 \\
-1 & 2 & -1 & 0 & 0 & . & . & 0 & 0 & 0 \\
0 & -1 & 2 & -1 & 0 & . & . & 0 & 0 & 0 \\
0 & 0 & -1 & 2 & -1 & . & . & . & . & . \\
0 & 0 & 0 & -1 & 2 & . & . & . & . & . \\
. & . & . & . & . & . & -1 & 0 & 0 & 0 \\
. & . & . & . & . & -1 & 2 & -1 & 0 & 0 \\
0 & 0 & 0 & . & . & 0 & -1 & 2 & -1 & 0 \\
0 & 0 & 0 & . & . & 0 & 0 & -1 & 2 & -1 \\
0 & 0 & 0 & . & . & 0 & 0 & 0 & 0 & 0
\end{array}\right] .
$$

And also $\vec{f}$ and $\vec{\tau}$ are both the column vectors. By using the iterative procedure, (2) can be solved as follows [6]:

$$
\begin{gathered}
\vec{f}^{(n+1)}=\left(A^{(n) T} A^{(n)}+\gamma^{(n)} H\right)^{-1} A^{(n) T} \vec{\tau}, \\
A_{i j}^{(n)}=\int_{r_{j}}^{r_{j+1}} K_{i}(r, m) h_{j}^{(n)}(r) d r, \\
i=1,2, \ldots N ; \quad \text { (wavelength numbers), } \\
j=1,2, \ldots M ; \quad \text { (size interval numbers), }
\end{gathered}
$$

where

$$
\begin{gathered}
K_{i}(r, m)=\pi r^{2} K_{e}\left(r, \lambda_{i}, m\right), \\
h_{j}^{(n)}(r)=h_{j}^{(n-1)}(r) f_{j}^{(n-1)}(r), \\
\gamma^{(n)}=b \sum \frac{\left(A^{(n) T} A^{(n)}\right)_{i i}}{N} .
\end{gathered}
$$




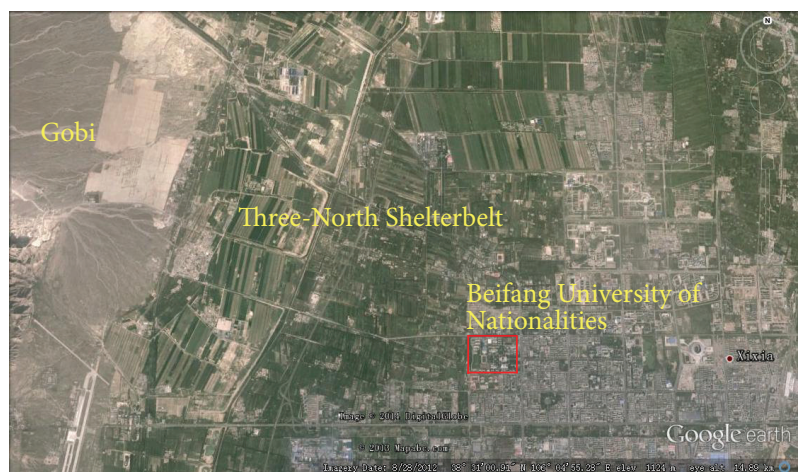

FIgURE 2: The campus location in Yinchuan.

The convergence criterion can be defined as [6]

$$
\left(\sum \frac{\left(f_{i}^{(n)}-1\right)^{2}}{M}\right)^{1 / 2}<\delta .
$$

For typical continent climate, the Junge function is well selected and it is in agreement with continent aerosol size distribution in the range of less than $2 \mu \mathrm{m}$, which can be written as

$$
n(r)=C r^{-(v+1)},
$$

where $C$ is coefficient and $v$ is the distribution constant and its range is from 2.0 to 4.0 .

In this paper, the Junge function is selected as initial rapidly varying function $h_{j}^{(0)}(r)$, and the slowly varying function $f_{j}^{(n)}(r)$ can be solved by interpolating linearly $n$ orders solution vector. After some iterative procedures, the stable solution of $h_{j}^{(n)}(r)$ is the unknown aerosol size distribution $n(r)[6]$.

\section{The Observation Experiments and Results Analysis}

For investigation of the aerosol number size distribution and its temporal-spatial evolution over the Yinchuan area, many observational experiments were carried out from September 2012 to October 2013 at Beifang University of Nationalities $\left(106^{\circ} \mathrm{E}, 38^{\circ} 13^{\prime} 29^{\prime} \mathrm{N}\right)$, Yinchuan, Ningxia, China. Figure 2 shows the campus location in Yinchuan. Yinchuan city is a medium sized city which is about 20 kilometers long from east to west and about several kilometers wide from south to north. From the east to the west Yinchuan city can be divided into three districts, namely, Xingqing district, Jinfeng district, and Xixia district. The population is mainly concentrated in Jinfeng district and Xingqing district. Beifang University of Nationalities is located at the west of Xixia District, namely, in the west of Yinchuan city. In the west and north of the campus there are the famous Three-North Shelterbelt and the Gobi desert that is in the eastern foot of mountain helan, and hence the population is very small.

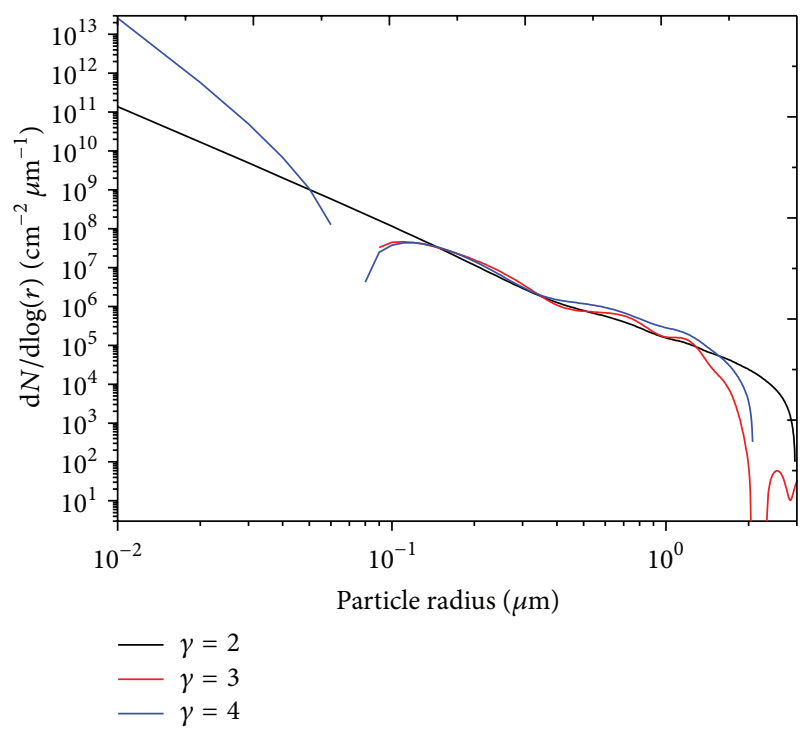

FIGURE 3: The determination of parameters $v$ of Junge function.

A sun photometer CE-318, which is installed at teaching building no. 17, is employed to record the direct solar radiation data. Every day the sun photometer works from about 8:00 to 17:00 Beijing time and automatically records the data except on the days when the sun was obscured by clouds and the rain, or when snow or sand dust occur. Up to now a total of 14235 measurements were carried out. In this paper, the seasons corresponding to the months are defined as follows: Autumn is from September to November, Winter is from December to February, Spring is from March to May, and Summer is from June to August. Considering that aerosol type of this area mainly belongs to sand dust particles, in inversion process the complex refractive index $m$ is assumed to be $1.5-0.01 i$ [13]. Moreover, according to their sizes and production mechanisms, the atmospheric aerosol can generally be divided into three types, namely, nucleation mode $(0.001 \mu \mathrm{m}<r<0.1 \mu \mathrm{m})$, accumulation mode $(0.1 \mu \mathrm{m}<$ $r<1.0 \mu \mathrm{m})$, and coarse mode $(r>1.0 \mu \mathrm{m})$.

In 1963, Junger used power function to describe the relation between logarithm of particle number concentration and logarithm of the particle radius. In the extinction method mentioned above, the Junge distribution function is selected as the initial rapidly varying function. The selection of parameter $v$ value in (7) is given special attention in inversion process. For determination of reasonable value of the parameter $v$, some comparisons were made. Figure 3 shows that the size distribution curves under different parameters $v$ of initial Junge function. It can be seen that when $v=4.0$ or 3.0, the retrieved size distribution curve is nonsmoothing, noncontinuous, and retrieval process is instable; but when $v=2.0$ the retrieval process is convergent. Because extinction factor is not sensitive to extinction effect of large diameter giant particle, the extinction method only is used to inverse the particle size distribution with diameter from 0.1 to $5 \mu \mathrm{m}$, and especially for the large particle with diameter from 0.1 to $1 \mu \mathrm{m}$ the inversion results are more stable. Extinction method 


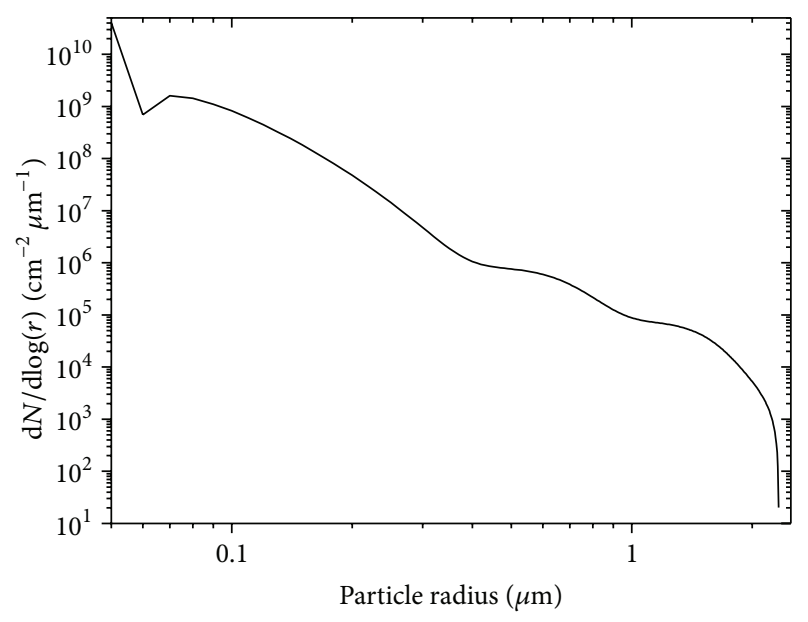

FIGURE 4: The averaged size distribution of the whole observation period.

is less sensitive to the selection of initial function in the proper range, and in a certain error range the selection of initial function is allowed to exist with a certain difference. Nevertheless, in order to make inversion result closer to the true result, choosing the more ideal initial function and more reasonable smooth constraints will be required [14]. Therefore, when Junge function is selected as initial rapidly varying function, the computed size distribution cannot always be in good agreement with the real distribution in the whole size range; that is, in some size range the retrieval discrepancy is small, but in other size range the large discrepancy may exist. Reasonable selection of initial function is also very important in stabilizing the inversion process. In this paper, the particle diameter is within 0.1 to $5 \mu \mathrm{m}$, and hence the retrieved size distribution can be in good agreement with the real distribution in the whole size range.

Figure 4 shows the averaged number size distribution during the whole observation period. It is obvious that the averaged size distribution basically satisfies the Junge function. However, there are two obvious peaks in the range from 0.01 to $2 \mu \mathrm{m}$, which located at $0.6 \mu \mathrm{m}$ of the accumulation mode and $1.4 \mu \mathrm{m}$ of coarse mode, respectively. As can be seen from Figure 4, in Yinchuan area the aerosol particle number size distribution is bimodal structure with two peaks located at the accumulation mode and coarse particles, respectively. As mentioned above, Yinchuan area, located at the arid region surrounded by three deserts, is an important transportation path and origin of sand dust that lies in the north of China. Under such natural conditions and atmosphere environment, the first aerosol source in Yinchuan area is very strong, and hence sand dust particles with larger size are dominant in atmosphere aerosol, and the concentration of aerosol particles in the accumulation mode and coarse mode is much higher than that of many cities of developed countries. Also, the number size distribution of Yinchuan area has some similar features with the other cities located at dust source area in the north of China, such as Ejin Banner and Dongsheng [6].
Figure 5 shows the monthly averaged AOD and seasonal averaged number size distribution from September 2012 to October 2013. In Figure 4(a) the averaged AOD value in Spring is the largest and that in Autumn is the smallest. In the Spring over the Yinchuan area and its surrounding area, the climate is very dry, soil is naked, and big wind blows the sand dust into the air easily; therefore, sand-dust weather is frequent. In fact in Spring 2013, several serious sanddust storm processes occurred. But in Autumn of Yinchuan, rainfall is obviously more than other seasons; therefore, the atmosphere is relatively clean. In Figure 5(b) it can be seen that the seasonal variation tendency of size distribution coincides with AOD value, but the number concentration in Spring is larger than that in Autumn with one order of magnitude.

In Winter, the heating needs of human beings increase the concentration of soot aerosol particles in the atmosphere; therefore, the influence of soot aerosol on particle size distribution should be considered. However, as mentioned above, the resident population around the campus is very small, and in Winter the strong northwest wind from Siberia can easily blow the soot aerosol particles near the school to the downwind area. Therefore, the geographical location and climate environment determine that the composition of atmospheric aerosol of Yinchuan area is composed by sand dust particles and that the complex refractive index is assumed to be $1.5-0.01 i$ in previous calculations which is basically reasonable.

Figure 6 shows the AOD and number size distribution taken on 19 September of 2012, a sunny and cloudless day. As seen in Figure 6(a), the AOD values of all wavelength bands increase from morning to afternoon. In the morning, the AOD value is lower; therefore, this kind of weather can be defined as the background weather; in contrast in the afternoon the AOD value became higher. This is because on that day there was no wind, and the aerosol particles suspending in the air could not be dispersed; therefore, the atmospheric deposition action was relatively low, the aerosol particles were accumulated gradually, and finally the AOD value reached the maximum in the afternoon. In fact, according to the observational results of Liu and Niu [1], the proportion of this type of AOD daily variation is 36 percent in the total observation period of one year in Inner Mongolia region which is a north neighbor of the Yinchuan area. In Figure 6(b) the size distributions are all conformed with the Junge distribution basically, and also at $0.6 \mu \mathrm{m}$ and $1.4 \mu \mathrm{m}$ there exist two peaks, which basically conformed to the averaged size distribution shown in Figure 4. Moreover, from the morning to the afternoon when the AOD value increased, the corresponding particles number concentration also became larger.

Figure 7 shows the AOD and the number size distribution on 1 November 2012. As shown in Figure 7(a) from 8 to 49 Beijing time the AOD values of all wavelength bands increased suddenly when a strong wind rolled up the sanddust of earth surface into the atmosphere. At 9:28 Beijing time a peak value of AOD appeared when the standard of sanddust weather was reached. After the peak, the value decreased gradually, at 11:09 the value returned to the normal level, 


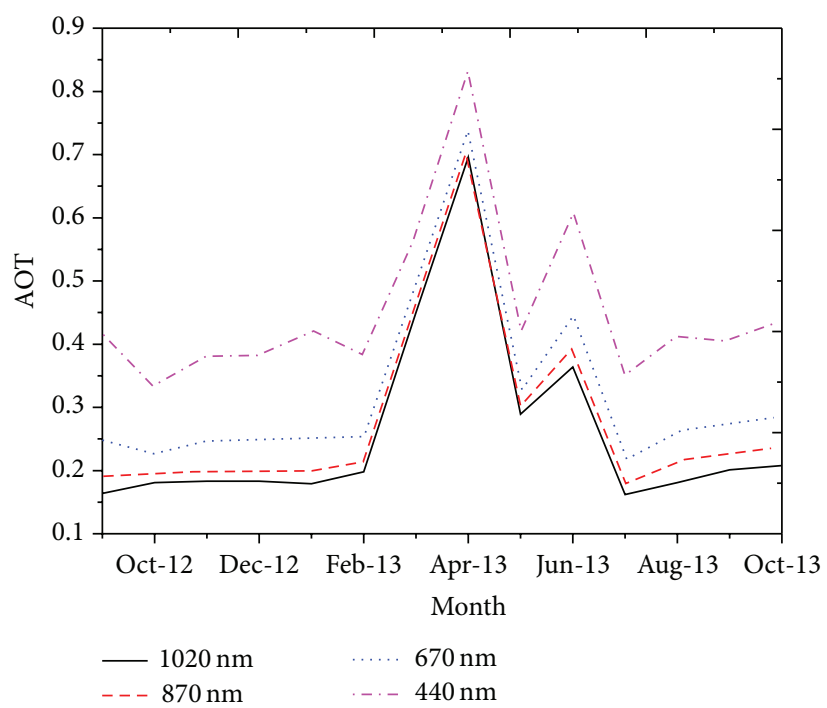

(a)

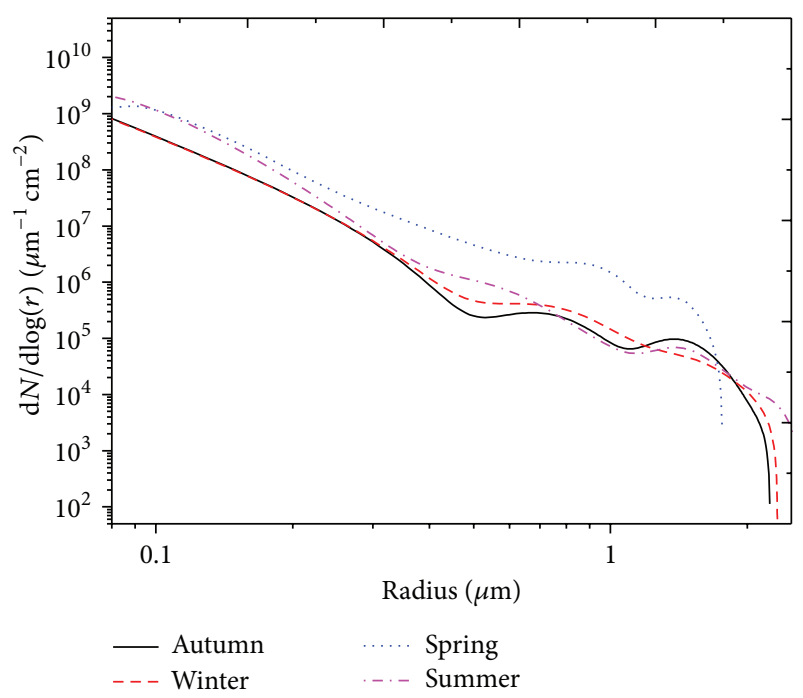

(b)

FIGURE 5: The monthly averaged AOD value and seasonal averaged size distribution of every month.

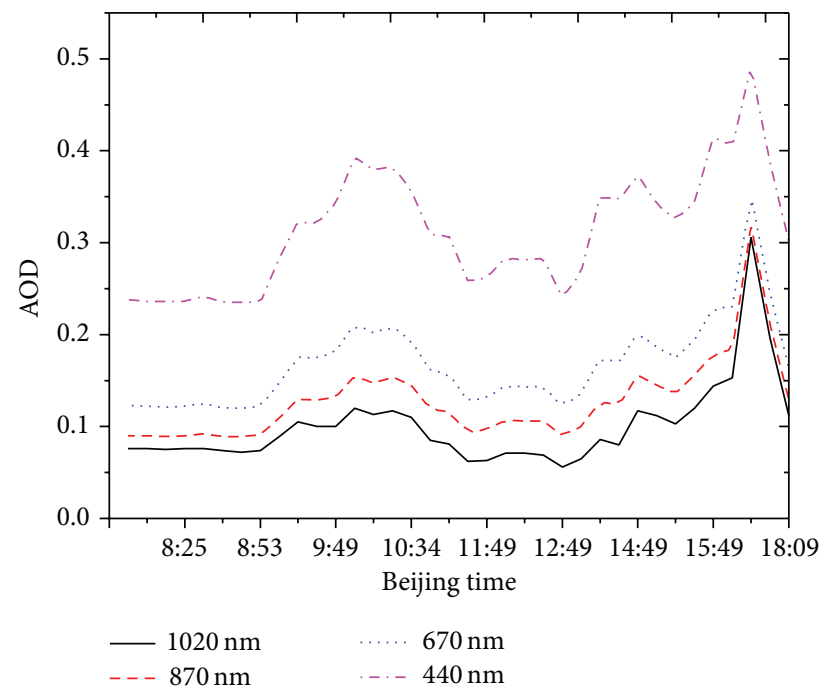

(a)

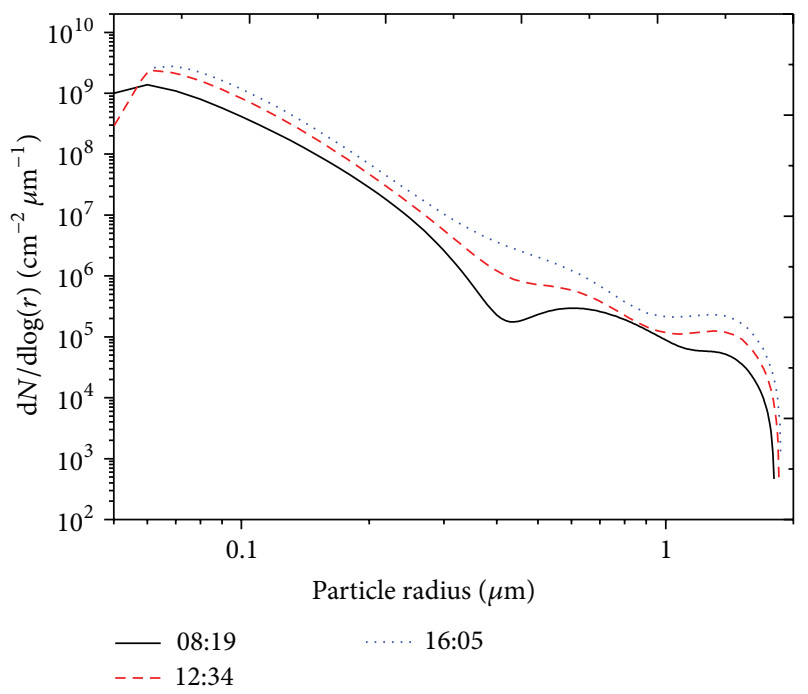

(b)

FIGURE 6: The AOD and size distribution of a sunny day taken on September 19, 2012.

the whole sand dust process only lasted about 2 hours, and the AOD varied from 0.3 to 1.15. Compared with Figure 6(b), the maximum number concentration at 9:28 Beijing time in sand dust weather is larger than that of background weather with one order of magnitude, and especially the number of concentration of large particles and giant particles, whose radius is larger than $0.2 \mu \mathrm{m}$ and $1 \mu \mathrm{m}$, respectively, is obviously larger than that of background weather. When the sand dust weather comes, concentration of coarse mode particles in the atmosphere will increase dramatically and will be greater than that of clear background weather. In fact with respect to producing extinction action for solar, the large particles and giant particles are the main factors which result in the increase of extinction coefficient and optical thickness; therefore, in sand dust weather the visibility is very low but $\mathrm{AOD}$ is very high [1].

At present, because of the limits of technical means and detection instruments, there are no very good methods to directly verify the atmospheric column particle size distribution retrieved from data of sun photometer. In fact some areas, which also belong to the main transportation path and origins of sand dust that lies in the north of China, have similar particle size distribution with Yinchuan area, which indirectly verify the feasibility of this study, such as Ejin Banner and Dongsheng, Tenggeli Desert $[6,14]$. Moreover, we use the synchronous measurement data taken by an aerodynamic particle size spectrometer APS-3321 in the same measuring place to indirectly verify the feasibility of this 


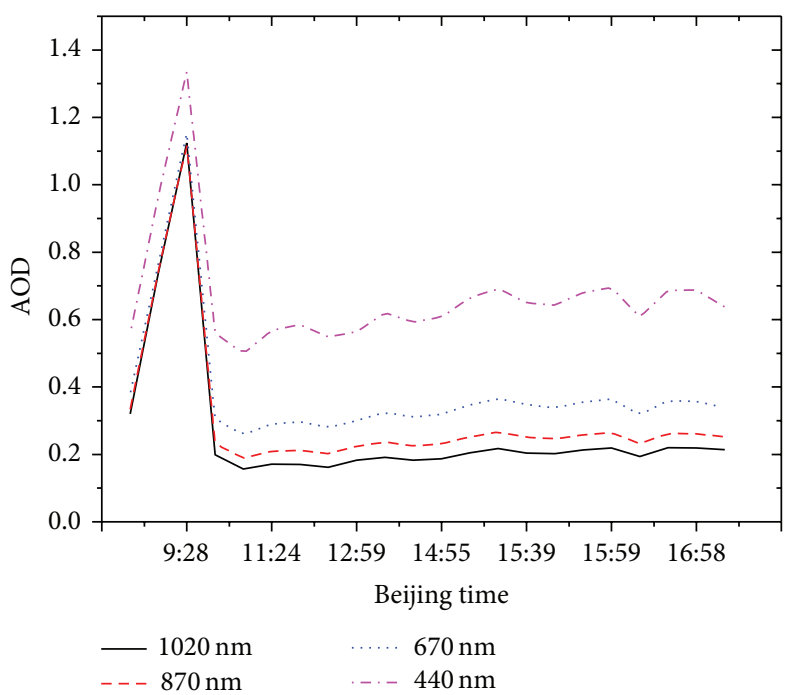

(a)

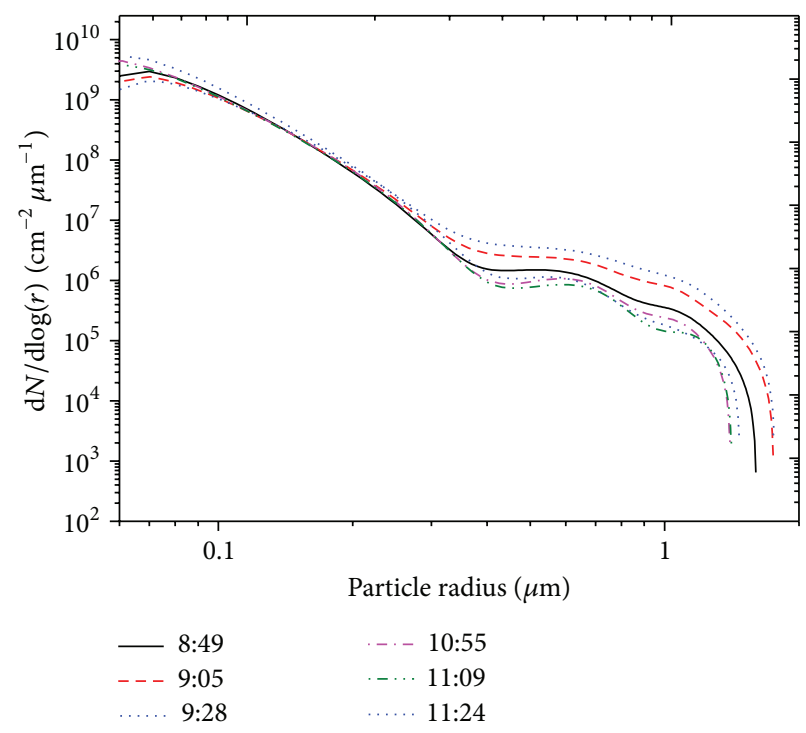

(b)

FIgURE 7: The AOD and size distribution of sand dust weather taken on November 1, 2012.

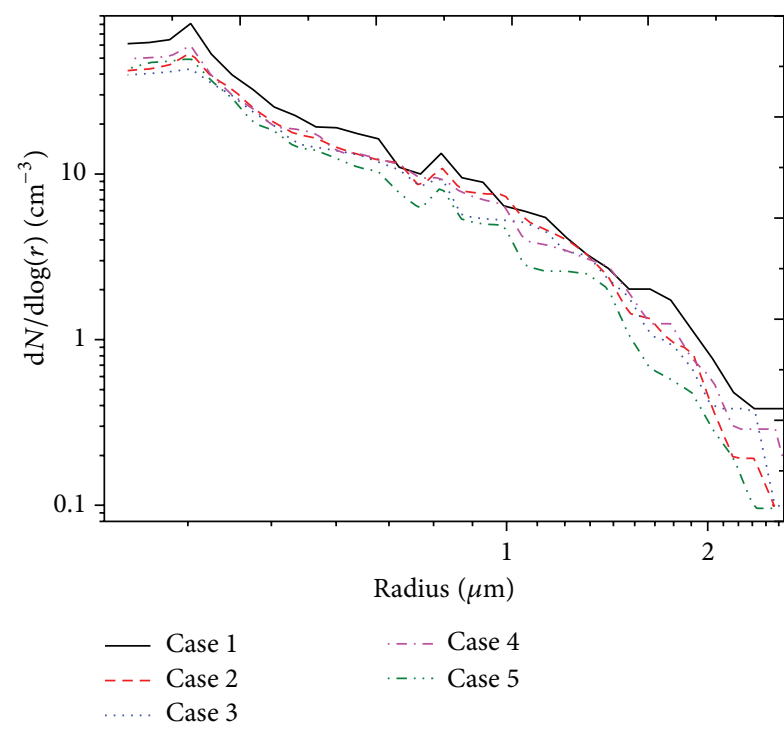

(a)

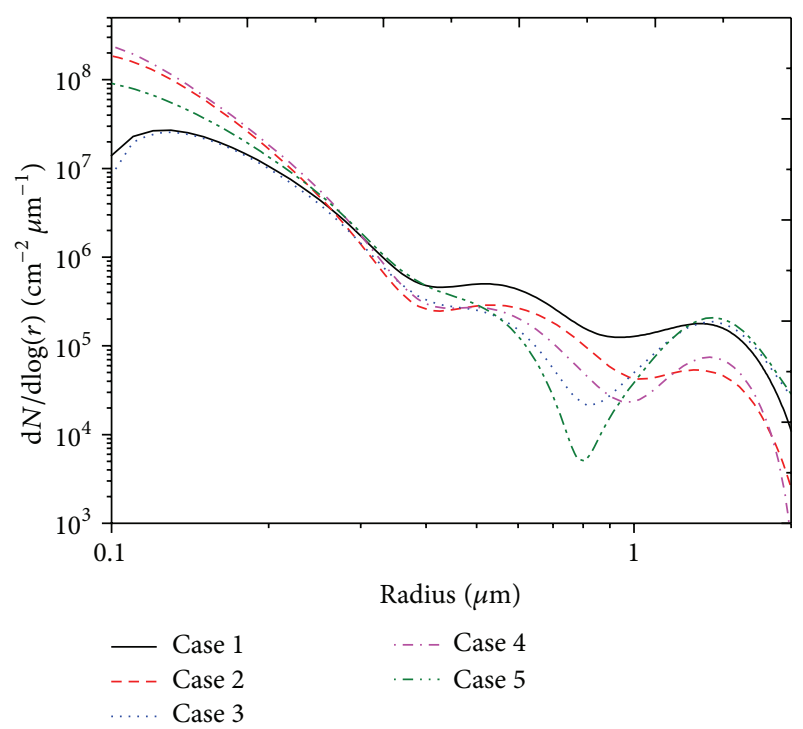

(b)

FIGURE 8: Some particle number size distributions obtained synchronously by sun photometer and APS-3321, respectively, during the observation period.

study. Figure 8 shows some particle number size distributions obtained synchronously by sun photometer and APS-3321, respectively, during the observation period.

In Figure 8, the number size distributions taken by APS3321 and sun photometer all basically satisfy the Junger distribution, but in Figure 8(a) there are two obvious peaks at the radius of about 0.35 and $0.75 \mu \mathrm{m}$, respectively, and in Figure $8(\mathrm{~b})$ the peaks appear at the radius of about 0.6 and $1.4 \mu \mathrm{m}$, respectively. It is clear that the shape of two types of size distributions is similar, which indirectly verify the results of this study, but the location of peaks is different.
This is because the measuring result of APS-3321 is ground data, but the particle size distribution retrieved by sun photometer is integral data through the whole atmosphere. The ground-air interface is one of important compositions of whole atmosphere, and the ground data measured by APS3321 represent the particle size distribution of ground-air interface [15]. The research of $\mathrm{Li}$ and Mao has shown that if the vertical atmospheric transportation is very enough and vertical mixing is also uniform, the size distribution of whole atmosphere aerosol column will be similar to that of ground [16]. In our observational data, there are some similar size 
distributions between APS-3321 and sun photometer, but no identical size distributions. This shows that, in observational period when the aerosol vertical mixing is relative strong, a lot of aerosol particles suspended in the atmosphere will originate from the ground-air interface, which can produce similar results as shown in Figure 8. The case between APS3321 and sun photometer in this study is similar to that of $\mathrm{Li}$ and Mao [16].

\section{Conclusion}

A sun photometer CE-318 is employed to measure systematically the direct solar radiation data from September 2012 to October 2013 over the Yinchuan region. The particle size distributions were retrieved from the AOD by use of extinction method. The experimental results were analyzed and some conclusions are obtained as follows. (1) The averaged size distribution of this area satisfies the Junge function basically; however, there are two obvious peaks in the range from 0.01 to $2 \mu \mathrm{m}$, which are located at $0.6 \mu \mathrm{m} 1.4 \mu \mathrm{m}$, respectively. (2) Because sand-dust weather occurs frequently, the particle number concentration in Spring is the largest and that in Autumn is the smallest, which coincides with AOD variation tendency. (3) The particle number concentration in sand dust day is larger than that of background weather with one order of magnitude, especially for the number concentration of large particles and giant particles.

\section{Conflict of Interests}

The authors declare that there is no conflict of interests regarding the publication of this paper.

\section{Acknowledgments}

This work was supported by the National Natural Science Foundation of China (NSFC) (no. 61168004), the Key Project of Chinese Ministry of Education (no. 211209), the Universities Science and Technology Project of Ningxia (no. 2011JY007), the Natural Science Foundation of Ningxia (no. NZ13094), and The West Light Talent Plan of the Chinese Academy of Sciences.

\section{References}

[1] F. Liu and S. Niu, "Optical thickness and size distribution of dust aerosol particles in Inner Mongolia," Journal of Nanjing Institute of Meteorology, vol. 29, no. 6, pp. 775-781, 2006.

[2] S. Niu, C. Zhang, and J. Sun, "Observational research on the size distribution of sand aerosol particles in the Helan Mountain Area," Chinese Journal of Atmospheric Sciences, vol. 25, no. 2, pp. 243-252, 2001.

[3] G. A. D'Almeida, P. Koepke, and E. P. Shettle, Atmospheric Aerosols: Global Climatology and Radiative Characteristics, A. Deepak, Hampton, Va, USA, 1991.

[4] J. N. Porter and A. D. Clarke, "Aerosol size distribution models based on in situ measurements," Journal of Geophysical Research D: Atmospheres, vol. 102, no. 5, pp. 6035-6045, 1997.
[5] V. M. Karyampudi, S. P. Palm, J. A. Reagen et al., "Validation of the Saharan dust plume conceptual model using lidar, Meteosat, and ECMWF data," Bulletin of the American Meteorological Society, vol. 80, no. 6, pp. 1045-1075, 1999.

[6] F. Li, J. Liu, and D. Lv, "Analyses of composite observation of optical properties of atmospheric aerosols in the late summer over some areas of North China," Scientia Atmospherica Sinica, vol. 19, no. 2, pp. 235-242, 1995.

[7] J.-D. Mao, D.-X. Hua, T.-Y. He, and M. Wang, "Lidar observations of atmospheric aerosol optical properties over Yinchuan area," Spectroscopy and Spectral Analysis, vol. 30, no. 7, pp. 20062010, 2010.

[8] V. Vitale, C. Tomasi, A. Lupi, A. Cacciari, and S. Marani, "Retrieval of columnar aerosol size distributions and radiativeforcing evaluations from sun-photometric measurements taken during the CLEARCOLUMN (ACE 2) experiment," Atmospheric Environment, vol. 34, no. 29-30, pp. 5095-5105, 2000.

[9] J. Heintzenberg, H. Muller, H. Quenzel, and E. Thomalla, "Information content of optical data with respect to aerosol properties: numerical studies with a randomized minimizationsearch-technique inversion algorithm," Applied Optics, vol. 20, no. 8, pp. 1308-1315, 1981.

[10] M. D. King, D. M. Byrne, B. M. Herman, and J. A. Reagan, "Aerosol size distribution obtained by inversion of spectral optical depth measurement," Journal of the Atmospheric Sciences, vol. 35, no. 11, pp. 2153-2167, 1978.

[11] S. Twomey, Introduction to the Mathematics of Inversion in Remote Sensing and Indirect Measurements, Dover, New York, NY, USA, 1977.

[12] Y. Zhang, Study of Laser Granulometric Analysis Algorithm. [The master paper of Xian], Technological University, 2010.

[13] K. T. Whitby, R. B. Husar, and B. Y. H. Liu, "The aerosol size distribution of Los Angeles smog," Journal of Colloid and Interface Science, vol. 39, no. 1, pp. 177-204, 1972.

[14] J. Xin, W. Zhang, J. Yuan, and L. Liu, “The spectrum distributions of dust aerosol over Tengger Desert retrieved by extinction method," Plateau Meteorology, vol. 23, no. 5, pp. 654-659, 2004.

[15] F. Li, J. Liu, and D. Lu, "Analyses of composite observation of optical properties of atmospheric aerosol in the late summer over some area of North China," Scientia Atmospherica Sinica, vol. 19, no. 2, pp. 235-242, 1995.

[16] J. Li and J. Mao, "Inversion of the property of atmospheric aerosol by pptical remote sensing," Acta Meteorologica Sinica, vol. 47, no. 4, pp. 450-456, 1989. 

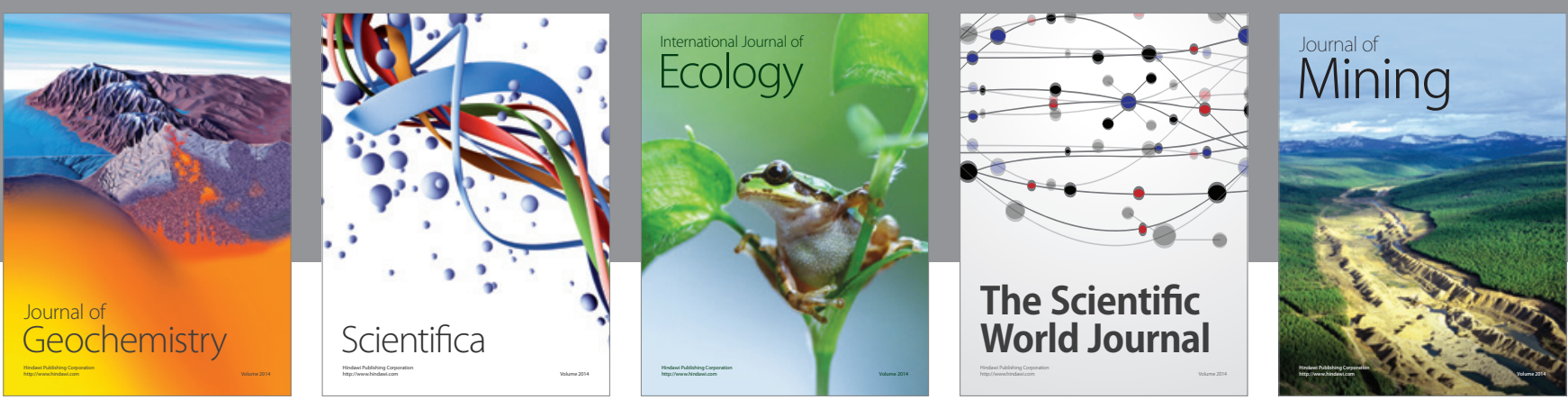

The Scientific World Journal
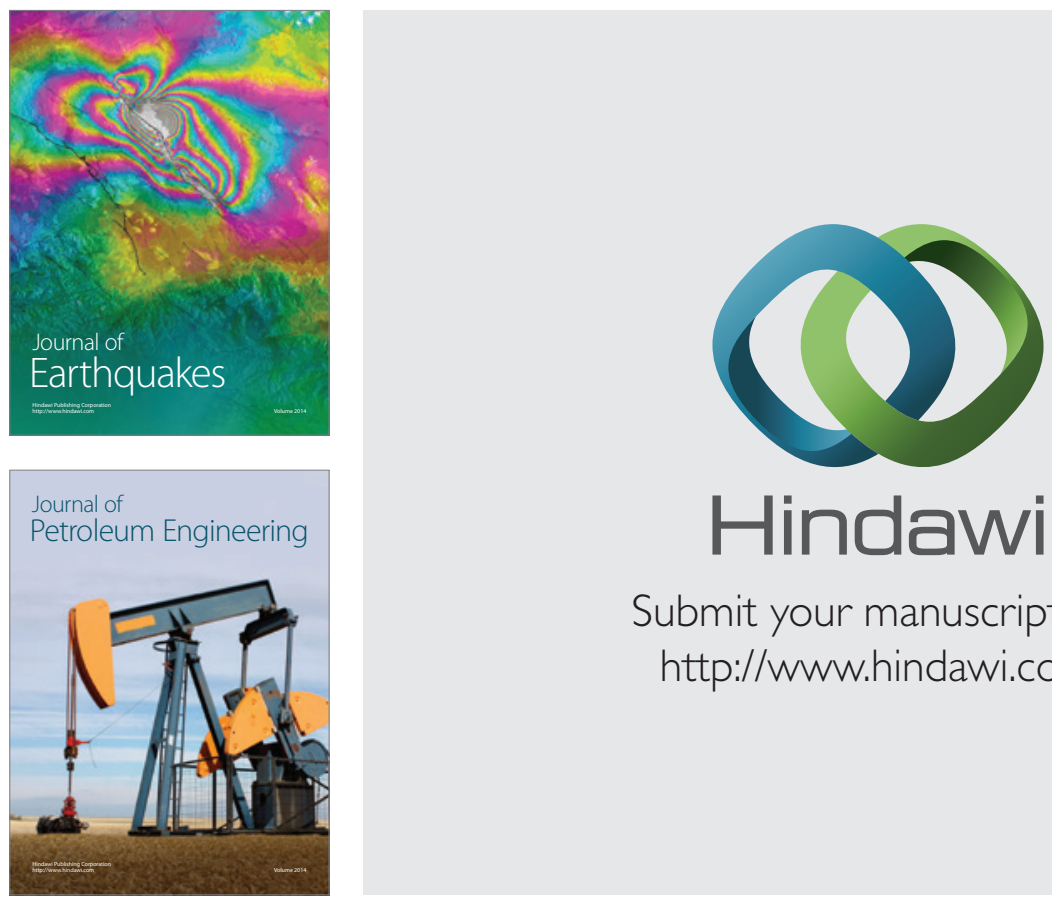

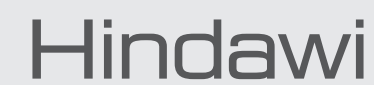

Submit your manuscripts at

http://www.hindawi.com
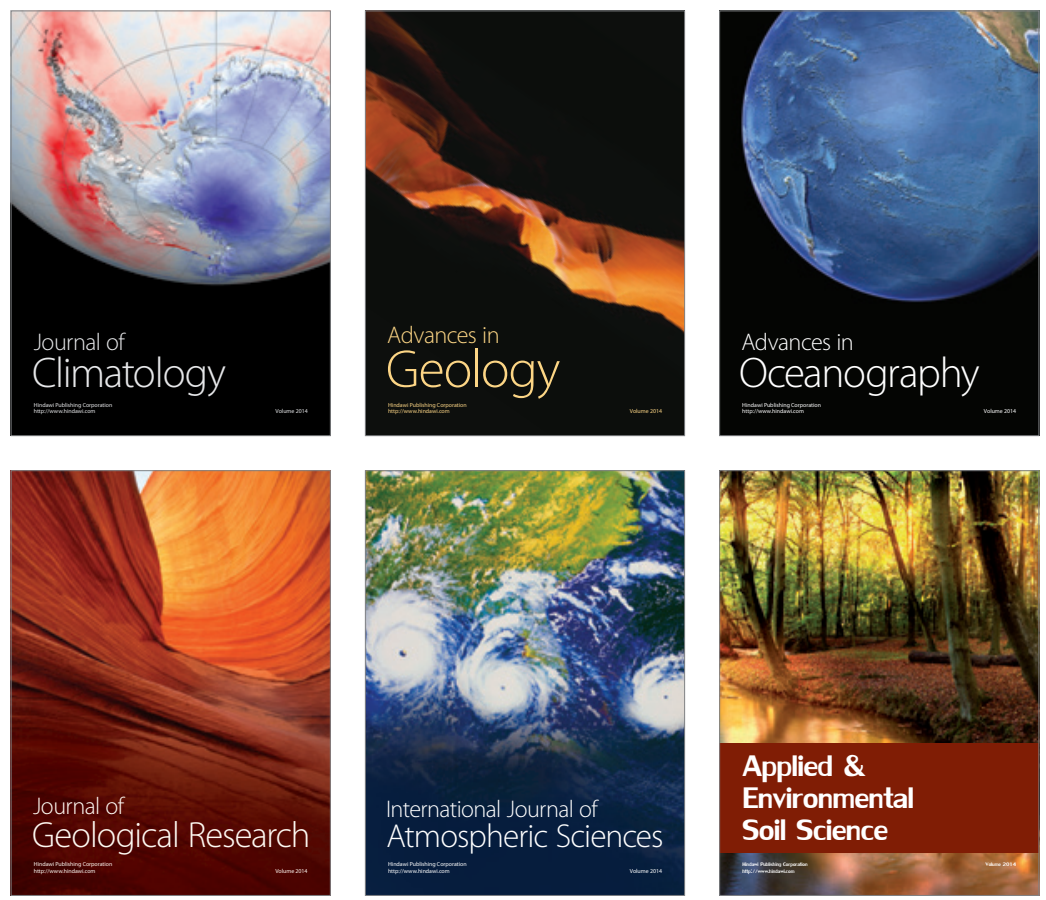
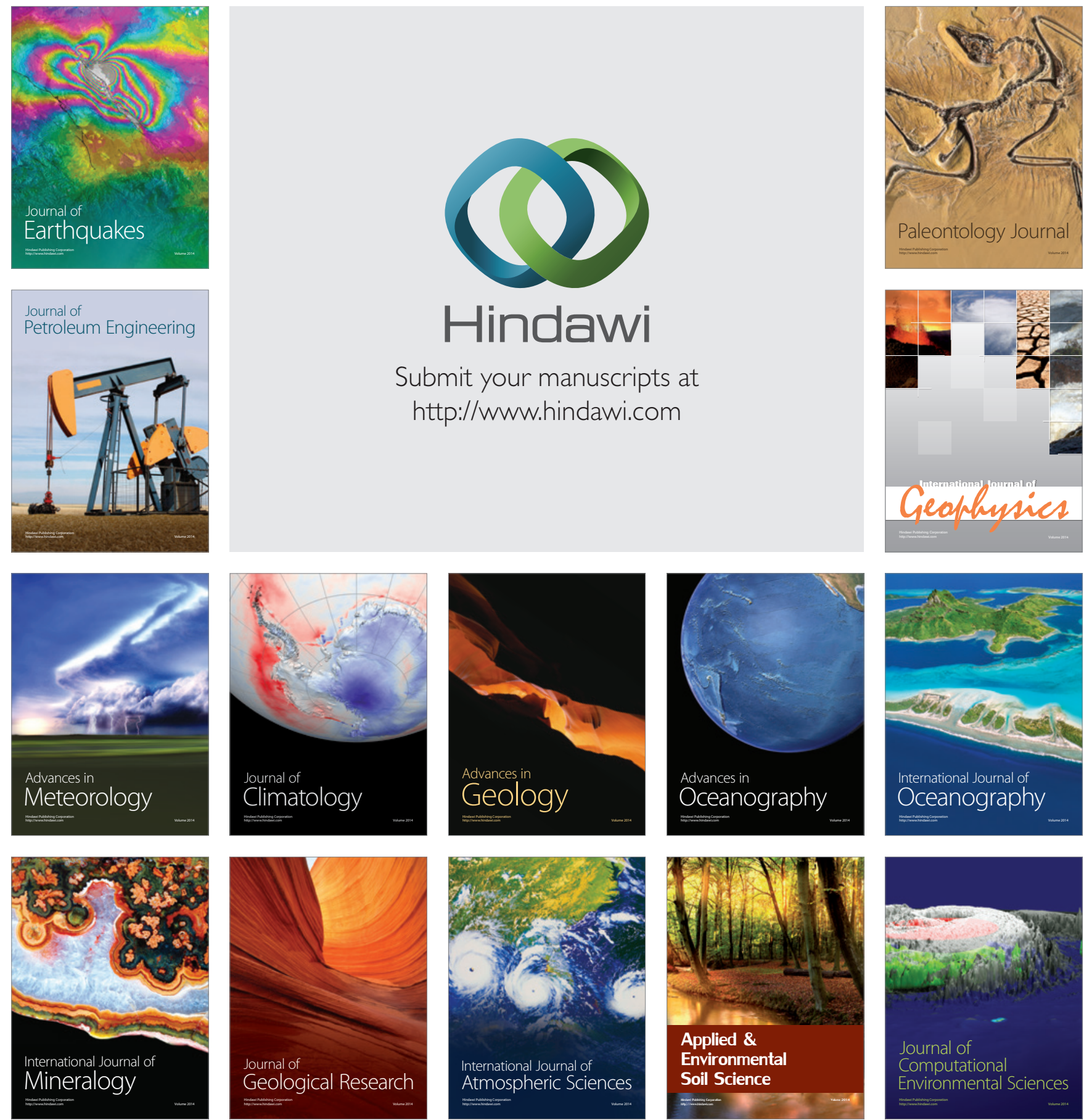